\title{
Environmental Sustainability through Textile Recycling
}

\section{Chavan RB*}

Institute of Sustainable and Appropriate Technology, Aurangabad, India

\begin{abstract}
The paper examines the process of achieving environmental sustainability through recycling of textile wastes. The recycling of textile waste can serve as a means of providing solutions to many economic, environmental and social issues. Though textile recycling has old history; in recent years it has assumed prime importance due to Fast Fashion culture in western world which has resulted in over consumption of textiles and corresponding waste generation. Today waste recycling has become a multibillion industry. Innovations are being made in terms of development of sorting machines, design inputs, innovative high value products to make recycling a profitable proposition. The paper also highlights in brief the efforts being made by various agencies and stake holders to achieve the aim of present $15 \%$ textile waste diversion rate to $75 \%$ diversion.
\end{abstract}

Keywords: Reuse; Recycling; Environmental sustainability; Waste diversion; Global warming; Climate change; Resource consumption

\section{Introduction}

For most of human history the world was sparsely populated and resources from forests to fisheries seemed unlimited. In the 20th century there were 1.65 billion people in the world, a population not much greater than that of China or India today. Society used resources and generated waste with little restraint and few concerns. This helped drive growth and improve the livelihoods of many millions of people.

The global population has now reached 7.2 billion and is estimated to be 9.6 billion by 2050 [1]. Resources are becoming increasingly scarce and climate change is a reality. This will have severe effects on weather patterns, water availability and agriculture [2]. There is loss of half the world's forests and degradation of an estimated $60 \%$ of the world's ecosystems [3]. When it comes to the environment, society is currently using resources at a rate that requires 1.5 planets [4]. These burning environmental problems arise from ever increasing volumes of worldwide production and consumption and the associated material flow waste [5].

Efforts are being made to create awareness for the catastrophic situation and educate people to reduce consumption and recycle products. Though recycling rates have increased around the world, but the majority of valuable processed materials are still thrown away rather than reused or recycled, leaving room for significant improvements and opportunities. Rising energy and raw material costs are putting pressure on businesses across the world. In the absence of bold decisions, price increases for energy, water, raw materials and manufacturing activities including textiles cannot be avoided. It is essential to understand that the $20^{\text {th }}$ century approaches to meet $21^{\text {st }}$ century demands are not affordable for sustainable development. Thus it is essential to incorporate the philosophy of sustainable development as an integral part of economic and environmental policy not only in developed countries but also in developing countries.

In view of the above futuristic view for sustainable development and business opportunities it is but natural to reduce the consumption of resources through recycling of products which are considered to be waste

Textile recycling has old history. The concepts of recycling, together with reduce $\&$ reuse have been ingrained in the social milieu of India. Traditional societies had in-built models of sustainability, through reuse and recycling. Production and consumption remained in harmony with each other and remained largely need driven [6].
In China, more than 2000 years ago, used clothing was shredded and hand-carded for blending with virgin fibers to make yarns. During the Napoleonic war, a shortage of wool for military uniforms advanced the need for recycling postconsumer fibers. In the United States, textile recycling is one of the oldest, yet most misunderstood, recycling industries [7].

Prior to World War II, the United States was a major importer of rags, cuttings, and other textile waste materials because the United States was a leader in mechanization for converting the used textiles into manufactured raw materials. The situation has been reversed since World War II. Now the United States exports tons of textile waste materials primarily because of the overconsumption of textile goods that eventually results in textile waste [8].

\section{Fashion as a Source of Over Consumption}

Globalization has made it possible to produce clothing at increasingly lower prices, prices so low that many consumers consider this clothing to be disposable [9]. Some call it "fast fashion", the clothing equivalent of fast food. Development of technology has enabled the industry to produce a plethora of products resulting in the depletion of natural resources and indiscriminate disposal habits [10].

Thus, fashionable goods contribute to consumption at a higher level than need. As consumers continue to buy, waste will continue to be created, further compounding the problem of what to do with discarded waste apparel, and home textile products. This presents a double-edged sword, in that while at the same time it stimulates the economy, it also gives rise to the increased problem of apparel and textile disposal [11]. Nonetheless, the recycling industry must cope with everything that the fashion industry has generated.

\section{Types of textile waste}

Like all wastes, textile waste originates from a number of streams

*Corresponding author: Chavan RB, Institute of Sustainable and Appropriate Technology, Aurangabad, India, Tel: +91-772-098-03-69; E-mail: rbchavan44@gmail.com

Received April 19, 2014; Accepted May 22, 2014; Published May 26, 2014

Citation: Chavan RB (2014) Environmental Sustainability through Textile Recycling. J Textile Sci Eng S2: 007. doi:10.4172/2165-8064.S2-007

Copyright: @ 2014 Chavan RB. This is an open-access article distributed under the terms of the Creative Commons Attribution License, which permits unrestricted use, distribution, and reproduction in any medium, provided the original author and source are credited. 
including the fiber, textile and clothing manufacturing industry, consumers, the commercial and service industries [12].

There are three types of textile wastes namely, pre-consumer, postconsumer and industrial.

Pre-consumer textile waste: Pre-consumer textile waste is the manufacturing waste that is generated by processing fibers, (natural or synthetic) and the production of finished yarns and textiles, technical textiles, nonwovens, garments and footwear, including off-cuts, selvages, shearings, rejected materials and/or B-grade garments, offcuts of saleable size etc. Pre-consumer textile waste is usually "clean waste". Firms either arrange their own waste disposal services or use council managed services and pay landfill fees according to how much is dumped.

Post-consumer textile waste: Post-consumer textile waste consists of any type of garments or household textiles (such as sheets or towels) that the consumer no longer needs and decides to discard, either because they are worn out, damaged, outgrown, or have gone out of fashion. This category has typically been of reasonable to good quality garment that can be recovered and subsequently recycled by another user as second-hand clothing, much of which is sold to third-world nations. Clothing that is unlikely to be worn again; may be shredded into fiber to be used in products similar in nature to those manufactured from pre-consumer textile waste.

Industrial textile waste: Industrial textile waste is generated from commercial and industrial textile applications including commercial waste from properties such as carpets and curtains, hospital refuse in addition to industrial applications such as filtration, conveyor belting, etc. Industrial textile waste is usually "dirty waste". Collection and chemical contamination issues render this category as the least likely to be recovered. A substantial proportion of these end-of-life goods are incinerated or dumped to landfills.

However, there is research currently being undertaken by a number of industries, including the carpet industry, to utilize this resource.

\section{Recycling of textiles waste}

The detail discussion on recycling of textile waste is out of the scope of present paper and is restricted to the point of environmental sustainability. The textile waste primarily can be recycled in the form of reuse and conversion into low value or value added products. Although the present emphasis is on recycling for value addition which is commonly known as up cycling.

The importance of recycling of textiles as a source of reduction in the use of virgin fibers and other resources such as water and energy can be understood from the following typical facts.

\section{Environmental impact of cotton and cotton/polyester t-shirt}

The resource consumption for cotton and cotton/polyester T-Shirt and $\mathrm{CO} 2$ saving are given in Tables 1 and 2 respectively [13].

\begin{tabular}{|c|c|}
\hline Resource consumption & Quantity \\
\hline Water & $2,400 \mathrm{gal}$ \\
\hline Fertilizers & $0.55 \mathrm{lbs}$ \\
\hline Pesticides & $0.02 \mathrm{lbs}$ \\
\hline Fossil fuels & $2.2 \mathrm{lbs}$ \\
\hline $\mathrm{CO}_{2}$ Emmision & $16.3 \mathrm{lbs}$ \\
\hline Other gases & $0.28 \mathrm{lbs}$ \\
\hline
\end{tabular}

Table 1: Material, Production and Transport Lifecycle Phases for a T-shirt weighing $0.25 \mathrm{~kg}$ (0.55 pound).

\begin{tabular}{|c|c|c|c|c|}
\hline Fibre & $\mathbf{C O}_{2}$ Saved $^{1}$ & $\begin{array}{c}\mathbf{C O}_{2} \\
\text { Photosynthesis }^{2}\end{array}$ & $\begin{array}{c}\mathbf{C O}_{2} \\
\text { Emitted }^{3}\end{array}$ & $\begin{array}{c}\mathbf{N e t}_{\mathbf{C O}_{2}} \\
\text { saved }\end{array}$ \\
\hline $100 \%$ Cotton & $16.3 \mathrm{lbs}$ & $-1.7 \mathrm{lbs}$ & $-0.4 \mathrm{lbs}$ & $14.2 \mathrm{lbs}$ \\
\hline $100 \%$ PET & $15.3 \mathrm{lbs}$ & $-0 \mathrm{lbs}$ & $-0.3 \mathrm{lbs}$ & $15.0 \mathrm{lbs}$ \\
\hline $58 / 42 \%$ PET/Cotton & $15.7 \mathrm{lbs}$ & $-0.7 \mathrm{lbs}$ & $-0.3 \mathrm{lbs}$ & $14.7 \mathrm{lbs}$ \\
\hline
\end{tabular}

${ }^{1}$ The savings are achieved by offsetting new clothing and including materials, production and transport.

${ }^{2}$ Through photosynthesis cotton plants would bind $1.65 \mathrm{lbs}$ of $\mathrm{CO}_{2}$ which is deducted from net savings.

${ }^{3}$ The dropping off, collection, processing and shipping of reusable clothing emits $\mathrm{CO}_{2}$ which is deducted.

Table 2: $\mathrm{CO}_{2}$ Savings from Reuse.

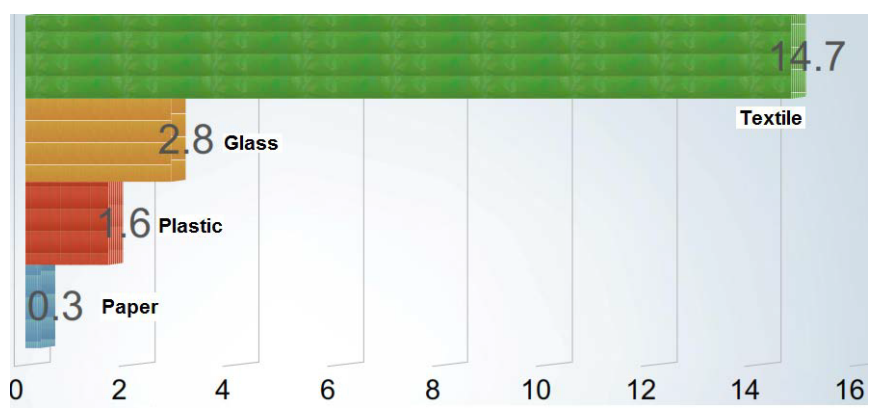

Figure 1: Tons of greenhouse gas emissions prevented per ton of reused or recycled.

(Source: www.stopwaste.org/.../usAgain-presentation)

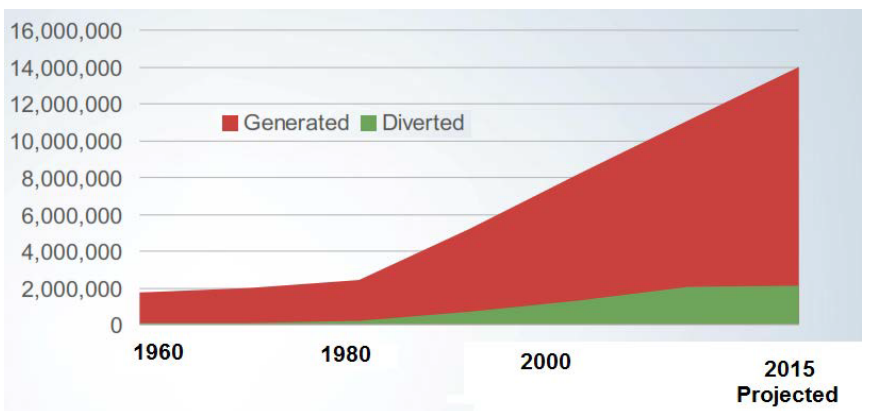

Figure 2: Textile waste generation and diversion rate.

(Source: www.stopwaste.org/.../usAgain-presentation)

\section{Greenhouse gas savings from textile recycling}

For every pound reused or recycled, textiles account for more greenhouse gas savings than paper, plastics and glass combined as shown in Figure 1.

\section{Textile waste generation and diversion rate}

In USA; by 2015 annual textile waste generation will increase to almost 14 million tons. Diversion is stagnant at $15 \%$ as illustrated in the following Figure 2 [13].

The aim is to achieve $75 \%$ diversion.

The enhancement of diversion of textile waste to convert into value added products could be achieved by adopting a proper strategy of

1. Increase convenience

2. Increase awareness

3. Measure the results 


\section{Convenience}

Convenience of location and access is important when diverting clothes for recycling and reuse. Some of the efforts needed to increase convenience are
Outdoor recycling bins
In-store collection points
Corporate collection
Multi-family units
Transfer stations
Public facilities - parks, libraries, fire stations
Schools Universities and prayer halls
Curbside collection
Events

\section{Increase awareness}

Government, non-profit and private enterprise

Partnerships can help

Educate the public on textile recycling.

\section{Measure results}

Include textiles in diversion planning and reporting.

\section{The effect of environmental impact of $75 \%$ textile waste diversion}

The effect of environmental impact of $75 \%$ textile waste diversion in terms resource saving, economic, and social issues are listed below

\section{Resource saving:}

4.2 trillion gallons of water would be saved. That's enough to supply 27.8 million homes.

17 million tons of $\mathrm{CO} 2$ would be saved. That's equivalent to taking 3.5 million cars off the roads.

- 7.5 million cubic yards of landfill space will be saved. That could fill the Empire State building 5.8 times!

\section{Economic:}

Increasing textile diversion to $75 \%$ would create many employment opportunities.

Social:

$70 \%$ of the world's population wears second hand clothing.

\section{International efforts to enhance diversion of textile waste}

The vision of every organization and municipality is to recycle all of its waste into usable products, there by closing the life-cycle loop. Science teaches us that matter and energy are not destroyed, they merely change state. Waste contains significant amounts of valuable resources that were once used as a raw material. Those products have lived their useful lives and have become waste, but they still contain the same matter end energy that went into their making. Logic suggests that by recovering textiles, the demand for virgin resources is reduced. Material washing and energy consumption still occur in the recycling processes, but they are considerably less resource intensive and polluting than the processes involved in manufacturing textiles from virgin fiber. Various stages of the recycling process also provide significant employment around the world.

Today, recovering textile waste is a multi-billion dollar global industry that performs a vital social and environmental function and provides employment for millions of people all around the world. An internet search on "textile waste" will elicit thousands of products or listings, including headings such as hosiery cuttings and clips, polyester tow, cotton shoddy, used clothing wiping rags, denim/jean clippings, $100 \%$ cotton yarn waste, silk fiber waste, etc.

All textile waste streams are often unrealized sources of valuable raw materials that can be repurposed or regenerated into saleable and usable products by intelligent collection, sorting, re-engineering and reprocessing. In essence, the liability of "waste" is turned into an asset often based on intellectual property (IP) which has been specifically developed. Processing machinery is also likely to be engineered to produce a specific product and thus the investment in developing regenerating capabilities is often large-scale. Products made by regenerating textile waste include acoustic textiles used for sound proof blocks, insulation, roofing felt, bank stabilization, and as pollution control filters. The list can be left to the imagination.

Some of the international efforts to divert textile waste into valuable products are only briefly mentioned. The details could be obtained from respective website references. The list is by means complete. The limited listing is indicative of the seriousness in the business of textile recycling for environmental sustainability.

\section{Commercial Organizations}

\section{Textile for Textiles (T4T)}

The quality of the recycled output depends on the accuracy of the sorting process. The T4T project uses an automated system which can sort textile waste, based on composition and color, quickly and accurately. An automated industrial sorting line using the NIRspectroscopy has been developed and demonstrated. Having analyzed the economic benefits, T4T upgraded and adapted its installation based on sorting requirements in relation to the envisaged products from the recovered fibers. Sorting system can be installed at a post-consumer textiles and clothing sorting plant. The installation will be able to sort large quantities of textile materials based on fiber composition (cotton, wool, polyester, blends, etc.), color, structure, coating or finish composition [14].

\section{Patagonia common threads recycling program}

Patagonia's 'Common Threads Recycling Program' uses a polyester fiber-to-fiber recycling system to make new garments from old. Patagonia has partnered with Japanese textile firm Teijin to implement a polyester product recycling program which started in Aug 2005. Under the program, Patagonia will recover from customers used Capilene undergarment products. Teijin will recycle them as polyester materials at a "fiber-to-fiber" recycling facility in Teijin Fibers' Matsuyama plant. In 2005, Patagonia began using a new polyester filament yarn containing 30\%-50\% post-consumer feedstock made from discarded polyester bottles, polyester uniforms, tents, and garments.

On the environmental benefits Patagonia states: "Research shows that the environmental impact of using worn-out clothing to make new polyester fiber is significantly lower than making the same fiber from virgin materials derived from petroleum. By diverting worn-out garments from landfills, we reduce solid waste. Diverting them from 
incinerators results in an energy savings of $76 \%$ and a $\mathrm{CO} 2$ emissions reduction of $71 \%$ " [15].

\section{Extended producer responsibility}

In the field of waste management Extended Producer Responsibility (EPR) is a strategy designed to promote the integration of environmental costs associated with goods throughout their life cycles into the market price of the products [16].

The concept of first introduced in Sweden with the following definition. EPR is an environmental protection strategy to reach an environmental objective of a decreased total environmental impact of a product by making the manufacturer of the product responsible for the entire life cycle of the product and especially for the take-back, recycling and final disposal [17].

\section{Take back program}

Many brands and retailers have shown interest in this issue and have started to take ownership of their products beyond retail, developing take-back programs with incentives.

It would not be impossible to name all current initiatives but here are a few examples:

Klattermusen: Swedish firm has launched the program rECOver that allows its used products to be returned to retailers, for cash [18].

Mammut: Swiss firm is providing collection boxes in its stores in Switzerland and partnering with a collector who is sorting the products and reusing or recycling them as much as they can [19].

Marks and Spencer: Since 2008, Marks and Spencer and Oxfam have been developing a cloth exchange program. Since then, they have managed to collect over 2,500 tons of clothing which are put to reuse or recycled [20].

\section{On line market places}

RecycleMatch: RecycleMatch [21] is an online marketplace to address the $\$ 90$ billion market for business recycling and zero waste with a closed bidding system designed specifically for corporations, municipalities, recyclers, and buyers of high quality commercial waste, in order to maximize the economic value of zero waste initiatives. There are hundreds of other exchange networks for industrial and municipal waste. Some of these are organized by non-profit organizations, government, or commerce chambers. They are free or inexpensive for companies to use them. Others are run by specialized companies and financed by a fee for announcement, or are consultancy providers who provide advice to waste producers on potential applications of their waste streams. Some are local, some regional or national, and some international. One can do an online search for 'waste exchanges' to find the one that meets your criteria. Some of the main ones include: Global Recycling Network [22], Euro recycle net [23], Worldwide Recycler's exchange [24].

\section{Government organizations/Associations/Institutes}

Sustainable Clothing Road Map: The UK government's Sustainable Clothing Roadmap launched in 2007, with the aim of improving the sustainability of clothing across its lifecycle from the crops that are grown to make the fabrics, to the design and manufacture of the garment, retail, use and end of life [25].

Sustainable Clothing Action Plan (SCAP 2020): Signatories and supporters of the SCAP 2020 commitment have pledged to play their part in reducing the carbon, waste and water footprints of clothing they supply or receive in the UK by $15 \%$ starting from the baseline year of 2012. 56 organizations have signed up to the commitment. Signatories and supporters represent more than $40 \%$ of UK retail sales, collectors, recyclers and charities [26].

BIR: The Bureau of International Recycling represents over 750 member companies from the private sector and 40 national associations in more than 70 countries. Together, these members form the largest international recycling federation. One of their expertise divisions is the industry of the textiles commodities [27].

SMART: Founded in 1932, the Secondary Materials and Recycled Textiles Association is composed of companies from the United States, Canada, Mexico, South and Central America, Europe, and PacificRim countries who are involved in every phase of the textile recycling industry: Reclaiming, converting, and recycling textiles and secondary materials [28]

\section{Green Growth: New methods for recycling plastic and textile waste}

Finding new methods to process waste and utilize it as a resource is among the Nordic Prime Ministers' green growth priorities. A new initiative, Resource Efficient Recycling of Plastic and Textile Waste, has been launched. The aim is to ensure that reuse will be given top priority. The objective is to develop Nordic waste collection and waste treatment methods, as well as new business models that contribute to green growth and can be exported to the rest of the world. In addition, the project will develop an Extended Producer Responsibility model, specifying producer's involvement in the effort to recycle their products [29].

\section{Conclusion}

The issues due to textile waste generation are related to over consumption of textiles in western world. The diversion of old textiles for reuse meets the requirements of clothing for $70 \%$ of the population in developing countries. Like other wastes, textile waste disposal through landfill and incineration is responsible for global warming. Though textile recycling has old history, today it has become multibillion industry producing innovative high value products. Many agencies and stake holders are making efforts to contribute towards the aim for saving in resources of raw materials, energy water etc. and reducing the impact on environment for sustainable development. In future textile recycling would be as important industrial activity as textile manufacturing.

\section{References}

1. UN report (June 13, 2013) World population projected to reach 9.6 billion by 2050.

2. Inter-governmental Panel- IPCC (2000) Climate Change Special Report on Emission Scenarios.

3. Prosperity without growth (2011) The transition to a sustainable economy, Sustainable Development Commission.

4. WWF (2010) Living Planet Report.

5. UNEP (2007) Global Environmental Outlook 4

6. Varsha G (2012) Ajit Khare Value Creation in post-consumer apparel waste: a study of urban-rural dynamics in India. NIFT, India.

7. Nousiainen P, Talvenmaa-Kuusela P (1994) Solid textile waste recycling Pape presented at the Globalization-Technological, Economic, and Environmental Imperatives, 75th World Conference of Textile Institute, Atlanta, USA. 
8. Jana MH (2006) Digging for Diamonds: A Conceptual Framework for understanding Reclaimed Textile Products. Clothing Textiles Res J 24: 262275

9. Claudio L (2007) Waste couture: environmental impact of the clothing industry. Environ Health Perspect 115: A448 - A454.

10. http://en.wikipedia.org/wiki/Fast-fashion.

11. Katkar PM, Bairgadar SM (2010) Textile waste recycling Textile Review.

12. Caulfield K (2009) Sources of textile waste in Australia. Apical International, Australia.

13. Wallander M (2014) Increasing the diversion of textiles.USagain.

14. www.textiles4textiles.eu/.

15. http://www.patagonia.com/us/common-threads.

16. OECD (2001) Extended producer responsibility: A guidance manual for governments Paris, France.

17. Thomas Lindhqvist (1993) The concepts of extended producer responsibility and product. USA.
18. www.klattermusen.se.

19. http://www.mammut.ch/cr_planet_ico.html

20. http://www.oxfam.org.uk/shop/content/

21. http://www.recyclematch.com/landing/homelandingpage

22. http://www.grn.com/a/1400.html

23. http://euro.recycle.net/

24. http://www.recycle.net/

25. www.defra.gov.uk/publications/files/pb13461-clothing-actionplan-110518.pdf

26. www.wrap.org.uk

27. www.bir.org/industry/textiles

28. www.smartasn.org

29. http://nordicway.org/2013/10/new-methods-for-recycling-plastic-and-textilewaste/ 